\title{
A Multicenter Study of the Light Visor for Seasonal Affective Disorder: No Difference in Efficacy Found Between Two Different Intensities
}

Norman E. Rosenthal, M.D., Douglas E. Moul, M.D., Carla J. Hellekson, M.D., Dan A. Oren, M.D., Arlene Frank, Ph.D., George C. Brainard, Ph.D., Megan G. Murray, B.A., and Thomas A. Wehr, M.D.

Fifty-five patients with winter seasonal affective disorder (SAD) were treated with a light visor, a newly developed potable light-delivery system, in a controlled parallel dsign. A dim (400 lux) visor was compared with a Inight (6000 lux) visor for either 30 or 60 minutes in the moming for 1 week. Response rates for these two treatments were $36 \%$ and $56 \%$, respectively; the duration of treatment sessions did not affect outcome. There was no evidence that the brighter visor was superior in efficacy to the dimmer one. Significantly greater relapse occurred following withdrawal of the dimmer visor. Alternative explanations for these findings are that the light visor is acting as a placebo or that it is equally effective over a wide range of intensities.

[Neuropsychopharmacology 8:151-160, 1993]
Ur wORDS: Seasonal affective disorder; Phototherapy; Light; Circadian rhythms; Seasons; Depression

The efficacy of bright-light therapy in the treatment of minter seasonal affective disorder (SAD) (Rosenthal et d. 1984) has been well established (for reviews see Rosenthal et al. 1988; Terman et al. 1989a; Terman and Terman 1991; Oren and Rosenthal 1992). Traditionally, treatment has been administered by having patients sit in front

From the Clinical Psychobiology Branch, DIRP, National Institute d Mental Health, Bethesda, Maryland (NER, DEM, DAO, MGM, TAW); the Providence Sleep Disorders Center, Providence HospiSeattle, Washington $(\mathrm{CJH})$; Brookside Hospital, Nashua, New Himpshire (AF); and the Department of Neurology, Jefferson Medical Colege, Philadelphia, Pennsylvania (GCB).

Address reprint requests to: Norman E. Rosenthal, M.D., Chief, Section on Environmental Psychiatry, Clinical Psychobiology Branch, Nional Institute of Mental Health, Building 10/4S-239, 9000 Rockville Fie, Bethesda, Maryland 20892.

Received June 12, 1991; revised January 28, 1992 and April 17, 1992; copted May 1, 1992. of light boxes, which some patients have found constraining. To obviate this inconvenience, we developed a portable head-mounted light-delivery system (Rosenthal and Wehr, unpublished observation 1988; Brainard and Benson, unpublished observation 1988; Stewart et al. 1990; patent: \#4,911,166, a portable light-delivery system). We tested the efficacy of this device by comparing light visors of two different intensities, one above and the other below the putative threshold for therapeutic efficacy, as estimated from the results of earlier studies with conventional light boxes (Checkley et al. 1986; Isaacs et al. 1988; James et al. 1985; Rosenthal et al. 1984, 1985; Wirz-Justice et al. 1986). We hypothesized that the brighter visor would produce antidepressant effects superior to those of the dimmer one. The study was conducted at three sites: the National Institute of Mental Health (NIMH), Bethesda, Maryland; Providence Hospital, Seattle, Washington; and Brookside Hospital, Nashua, New Hampshire. The present report documents the outcome of this study and discusses its implications. 


\section{MATERIALS AND METHODS}

\section{Subjects}

Participants in the study were 55 adult volunteers recruited via community referral channels and the local news media. To be included, subjects had to meet the SAD criteria of Rosenthal et al. (1984) and the DSMIII-R criteria for a lifetime history of major depression (Spitzer et al. 1989). One exception to the criteria of Rosenthal et al. (1984) was the inclusion of patients with a past history of other Axis I psychiatric disorders, provided there was no active evidence of the disorder at the time of evaluation. Patients were required to be in reasonably good physical health as determined by history, physical examination, electrocardiogram, routine bloodwork, and urinalysis. Patients with retinal diseases or cataracts, untreated hypothyroidism, or any serious medical conditions were excluded.

Taking medications was not in itself an exclusionary criterion provided that patients agreed to maintain their medications at fixed dosages throughout the study. Shift-workers and others who were unable to maintain consistent sleep schedules throughout the study period were excluded. Those patients who had been receiving traditional light therapy were eligible, provided they discontinued that therapy for at least 2 weeks before entering the study. All subjects provided written informed consent.

\section{The Light Visor}

The head-mounted light-therapy device or "light visor" was developed collaboratively by investigators at the NIMH (N.E.R. and T.A.W.), the Biomedical Engineering and Instrumentation Program of the National Institutes of Health (Stephen B. Leighton, Sc.D.), and Jefferson Medical College (G.C.B.) and was supplied by Bio-Brite, Inc, Bethesda, Maryland. The visor consists of two light sources, one directed toward each eye, each set in a plastic hemisphere with a highly reflective metal coating behind translucent diffusing and mylar filters, which spread the light over a circular surface area approximately $7 \mathrm{~cm}$ in diameter (see Fig. 1). The visor is powered by a portable rechargeable battery source. The light is emitted from miniature 2.6-watt krypton incandescent bulbs and contains virtually no ultraviolet rays after it has passed through the mylar filter. The spectral power of the visor was measured with a McPherson monochromator with a Hamamatsu pho. tomultiplier and solid-state amplifier. This equipment was calibrated with a model 22A 200-watt quartztungsten lamp (Optronic Laboratories, Inc.) traceable to NIST (see Fig. 2). The metal hemispheres reflect the light toward the eyes, thereby maximizing the efficiency of the system. The diffusing filters help reduce the concentration of brightness in the center of the lightemitting surface. When the visor is worn as intended, the light-emitting area occupies the upper half of the visual felds allowing the wearer to see his surroundings while receiving treatment.

To test the efficacy of the visor, we chose two different illuminances, one brighter (approximately $6000 \mathrm{lux}$ ) and one dimmer (approximately $400 \mathrm{lux}$ ). The illuminance of the bright visor was chosen because it falls in the range of previously active light-treatment conditions, and the illuminance of the dim visor falls in the range of light-treatment conditions found previously to be relatively ineffective (Rosenthal et al. 1988; Terman et al. 1989a; Terman and Terman 1991; Oren and Rosenthal 1992). Both visors had the same reflec. tors, bulbs, ultraviolet filters, and batteries and were identical in their external appearance. Tocreate the dim. light condition, a $1 \mathrm{ohm}$ resistor was inserted in series with the battery pack. To ensure correct and consistent light intensities, light output was measured before and after each week of use and new bulbs were installed routinely before each treatment week. Illuminance measurements were taken by positioning a light meter 5.8

Figure 1. Illustration of the light visor.

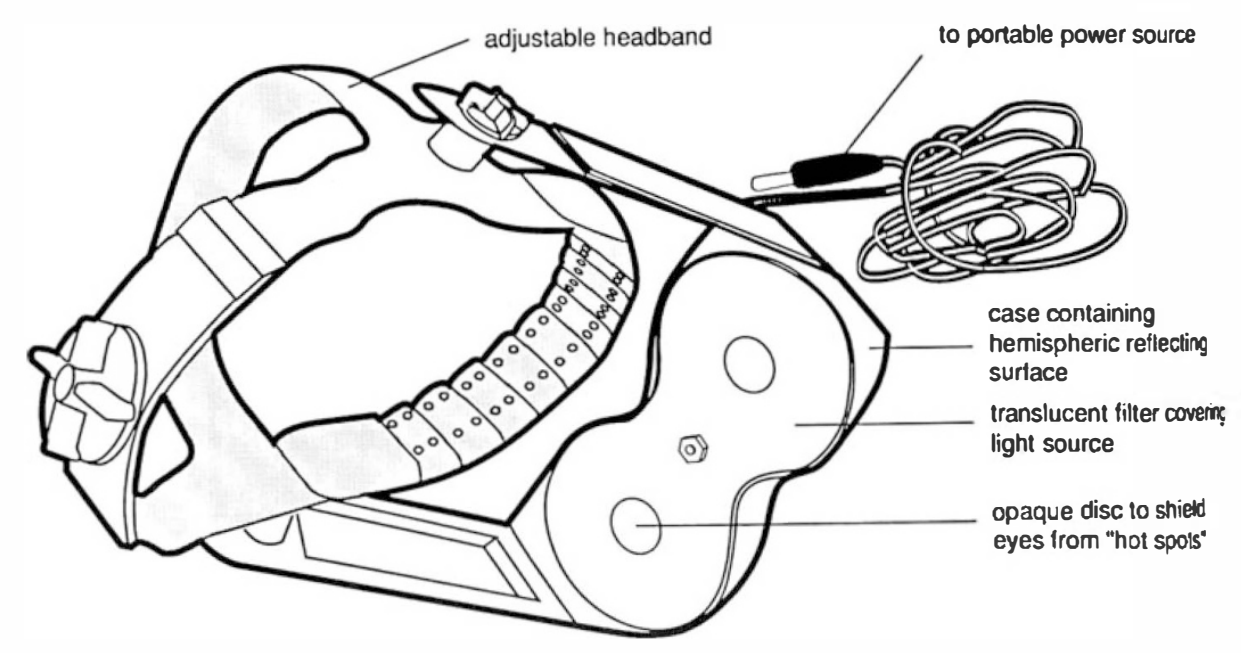




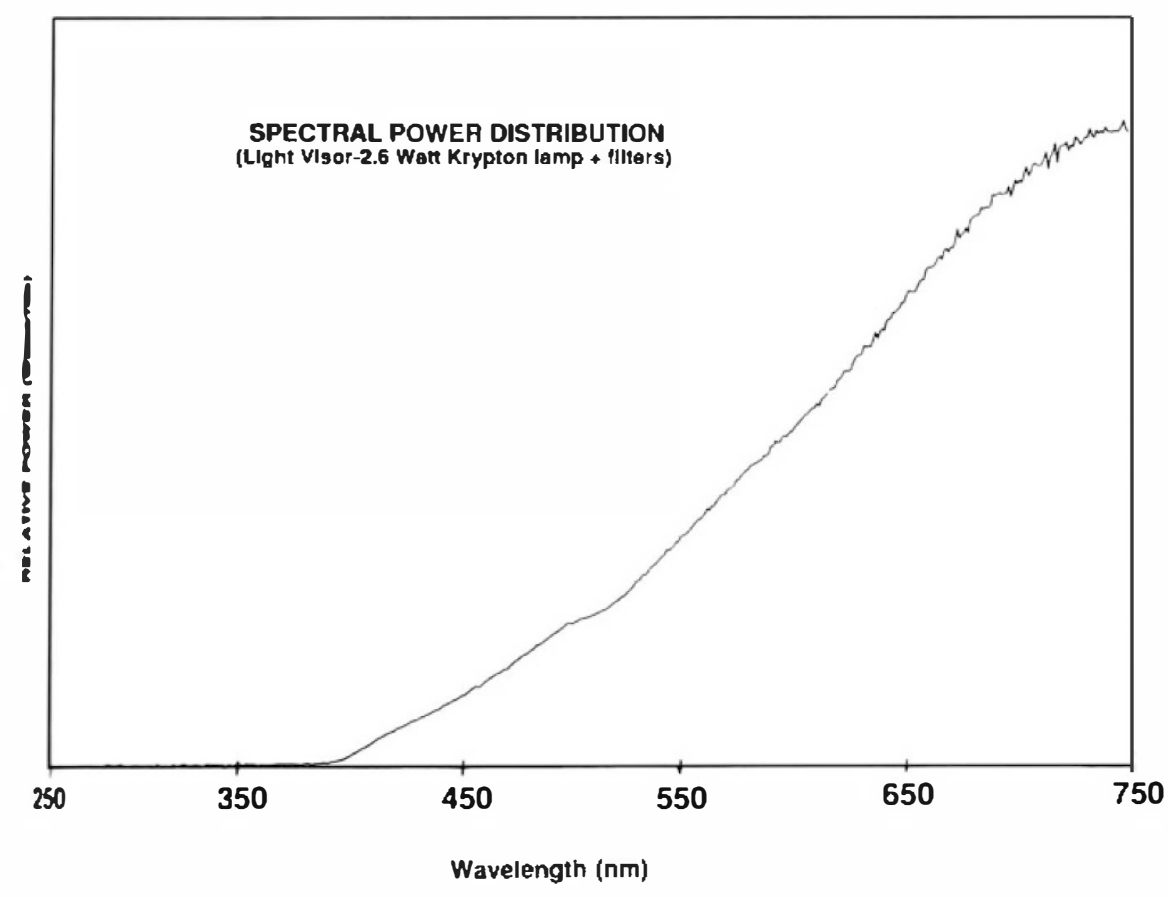

Figure 2. Spectral power distribution for the light visor used in this study. anfrom the diffusing surface where the wearer's eyes were expected to be. Measurements taken over 60 - and $3 \mathrm{O}$-minute treatment sessions showed the average visor illuminance decayed $20 \%$ and $15 \%$, respectively. Pabents recharged the battery pack each day during the sudy.

The maintenance records of the visors indicate that \& no point was any dim visor brighter than 415 lux (ange 300 to 415 lux), nor was any bright visor dimmer than 4000 lux (range 4000 to 7800 lux). No light source biled during the study.

\section{Study Design and Procedures}

We employed a randomized single-blind paralleltreatment design in which we comparedbright and dim visors over three phases, each lasting 1 week: baseline, reatment, and withdrawal. During the baseline period, patients were asked to adhere to consistent sleep-wake schedules because of the known antidepressant effects of sleep deprivation in nonseasonal depressives and the possibility that SAD patients might be similarly affected. In addition, we asked patients to keep a daily log of wake-up times since sleep deprivation has been reported to have maximum antidepressant effects in the later part of the night (Wehr 1990). Those on maintenance medications were asked to keep their dosage constant. We measured their mood levels on a weekly basis by means of the structured interview guide for the Hamilton Depression Rating Scale (SIGH)-SAD (Williams et al. 1988), from which we derived their 21item Hamilton Depression Rating Scale (HDRS) scores (Hamilton 1967). Patients were admitted into the treat- ment phase of the study if they had an HDRS score of 14 or more or a SIGH-SAD total score of at least 22 with a minimum of 10 on the HDRS.

Upon acceptance of patients into the treatment phase, we randomly assigned them to either the brightor dim-visor condition, stratified across centers and balanced with respect to the presence or absence of concomitant medications and a history of previous light treatment. We taught each patient to position the visor correctly in relation to the eyes, turned the lights on for 1 minute and evaluated each patient's expectations of the effectiveness of the treatment by means of a standard expectations questionnaire (Borkovec and Nau 1972). We did not inform the patients that we were testing two different visors, nor did we discuss with them our specific hypothesis. We told themonly that we were trying to determine whether the light visor was clinically effective and asked them not to discuss the study with any other participants. We requested that patients maintain their ambient lighting at the same level during their treatment sessions as it had been at that time of day during the baseline week. We asked them to restrict their movements during treatments as we were concerned that those wearing the bright visor might bump into things as a result of glare.

On the basis of earlier studies that showed that 30 minutes of treatment with 10,000 lux is effective for winter SAD (Terman et al. 1989b), we initially selected 60minutes of light treatment in the morning, predicting that it would be more effective for the 6000-lux than for the 400-lux condition. We asked patients to wear their visors at a consistent time between 6:30 A.M. and 8:30 A.M. for seven consecutive mornings. Preliminary anal- 
ysis of the first 21 subjects revealed that the dim visor was yielding surprisingly good results, making it less likely that the predicted difference betweengroups, that is the predicted superiority of the bright over the dim visor, would be detected with the initial treatment design. In an attempt to elicit this predicted difference in the remaining subjects, we decreased the daily treatment time for the remaining 31 subjects to 30 minutes, at the same time in the morning as before.

After each treatment week, we withdrew patients from light for 1 week and measured their mood once again.

No specific measures were taken to evaluate the effects of the light visor on the eyes since individuals with evidence of significant ocular pathology were excluded from the study and the illuminances emitted by both visors were well below typical outdoor levels (Thorington 1985) and within recommended indoor illuminances (Kaufman and Christensen 1987). We should note, however, that the value of such light level comparisons is limited by the fact that the light from the visor bears a fixed relation to the head and eyes and therefore cannot be as readily avoided as light emanating from the sky.

\section{Dependent Variables}

Mood was measured with the SIGH-SAD by raters blind to the patient's treatment status. To maximize reliability across centers, raters at all centers were given standard scoring instruction and their reliability was tested on 12 videotaped SIGH-SAD interviews of depressed patients. Reliability of raters was quite good both within and across centers (intraclass correlation $=0.98$ for raters in Bethesda and Nashua and 0.95 across centers). There were five raters at Bethesda, three at Nashua, and one at Seattle. Clinical care was provided by clinicians blind to which visor any particular patient received.

To estimate the amount of light actually entering the eye, we measured pupillary diameters of the patients in Bethesda by photographing the eye with a Polaroid camera fitted with a 1:1 lens (to avoid spherical distortion) and flash (to illuminate dark irises). Just before starting their treatment week, patients were photographed while wearing the visor with its lights on after 1 minute of exposure to the visor in the "on" position and in ordinary indoor lighting. Pupillary diameters were measured from the photographs by raters blind to the treatment condition. For logistical reasons, these measurements were made only at the Bethesda site.

Preliminary measurements (Waxler et al. unpublished results) were made of a single bright and a single dim visor, using the CapCalc Luminance Measurement System (National Research Council, Canada). Based on these initial luminance values and using pupil- lary sizes from subjects at the Bethesda site, rough estimates of retinal illuminance were made from the formula of Wyszecki and Stiles (1982). We collected information on side effects from a standard rating form, which patients completed at the end of the study.

\section{Statistical Analysis}

Hamilton Depression Rating Scale and SIGH-SAD scores between treatment conditions were analyzed in two ways: Analysis was performed by means of conventional analysis of variances (ANOVAs) with repeated measures and post-hoc $t$-tests where appropriate. In the ANOVA, there were three grouping factors (illuminance, site, and treatment duration) and one repeated measure (study phase); The second analysis involved dichotomizing the population into responders and nonresponders based on criteria previ. ously established by Terman et al. (1989). The results of this dichotomy were then analyzed by Fisher's exact tests, with appropriate corrections when durations were combined (Mantel and Haenszel 1959). To evaluate the possibleinfluence of prior light experience on response to light therapy, we ran additional ANOV As on HDRS and SIGH-SAD ratings, using the presence or absence of a history of light therapy as an additional grouping factor.

Wake-up times were analyzed by ANOVA with repeated measures and post-hoc $t$-tests where appropriate. A priori expectations and side effects were analyzed by appropriate parametric statistical measures.

To determine the association between response and retinal illuminance, correlations were performed between retinal illuminance values and the change in HDRS and SIGH-SAD total scores for the Bethesda group as a whole and separately for bright- and dimvisor subgroups. In all analyses, two-tailed significance levels were used. In those instances where multiple comparisons were performed, appropriate adjustments were made for the increased probability of making a Type I error.

\section{RESULTS}

\section{Clinical and Demographic Features}

The distribution of subjects across the three sites (Bethesda, Seattle, and Nashua), the two durations $(60$ and 30 minutes), and the two treatment conditions (bright and dim) are shown in Table 1. Most patients were seen in Bethesda and Seattle, with approximately the same number seen in each of these two places. Since the 60-minute treatment condition was the first para. digm used, and the study in Seattle was initiated slightly after the study in Bethesda, more patients were 
Table 1. Demographic Features of Study Subjects ${ }^{a}$

\begin{tabular}{|c|c|c|c|c|c|c|}
\hline & \multicolumn{2}{|c|}{$\begin{array}{c}\text { Hour } \\
n=21\end{array}$} & \multicolumn{2}{|c|}{$\begin{array}{c}\text { Half Hour } \\
n=34\end{array}$} & \multicolumn{2}{|c|}{$\begin{array}{c}\text { Total } \\
n=55\end{array}$} \\
\hline & $\begin{array}{l}\text { Bright } \\
n=10\end{array}$ & ${ }_{n=11}^{\operatorname{Dim}}$ & $\begin{array}{l}\text { Bright } \\
n=20\end{array}$ & $\begin{array}{c}\text { Dim } \\
n=14\end{array}$ & $\begin{array}{l}\text { Bright } \\
n=30\end{array}$ & $\underset{n=25}{\operatorname{Dim}}$ \\
\hline $\begin{array}{l}\text { Location: } \\
\text { Bethesda } \\
\text { Seattle } \\
\text { Nashua }\end{array}$ & $\begin{array}{l}7 \\
1 \\
2\end{array}$ & $\begin{array}{l}7 \\
2 \\
2\end{array}$ & $\begin{array}{r}6 \\
13 \\
1\end{array}$ & $\begin{array}{l}5 \\
8 \\
1\end{array}$ & & $\begin{array}{r}25 \\
24 \\
6\end{array}$ \\
\hline $\begin{array}{l}\text { Diagnosis: } \\
\text { Unipolar } \\
\text { Bipolar I } \\
\text { Bipolar II }\end{array}$ & $\begin{array}{l}9 \\
1 \\
0\end{array}$ & $\begin{array}{r}10 \\
1 \\
0\end{array}$ & $\begin{array}{r}20 \\
0 \\
0\end{array}$ & $\begin{array}{r}14 \\
0 \\
0\end{array}$ & & $\begin{array}{r}53 \\
2 \\
0\end{array}$ \\
\hline $\begin{array}{l}\text { Medication Status: } \\
\text { On antidepressants } \\
\text { On any medications }{ }^{b} \\
\text { On no medications }\end{array}$ & $\begin{array}{l}3 \\
6 \\
4\end{array}$ & $\begin{array}{l}1 \\
8 \\
3\end{array}$ & $\begin{array}{r}2 \\
5 \\
15\end{array}$ & $\begin{array}{l}2 \\
7 \\
7\end{array}$ & & $\begin{array}{r}8 \\
26 \\
29\end{array}$ \\
\hline $\begin{array}{l}\text { Sex: } \\
\text { Females } \\
\text { Males }\end{array}$ & $\begin{array}{l}9 \\
1\end{array}$ & $\begin{array}{r}10 \\
1\end{array}$ & $\begin{array}{r}18 \\
2\end{array}$ & $\begin{array}{l}9 \\
5\end{array}$ & & $\begin{array}{r}46 \\
9\end{array}$ \\
\hline $\begin{array}{l}\text { Age: } \\
\text { Mean } \\
\text { Standard Deviation }\end{array}$ & $\begin{array}{l}43 \\
13\end{array}$ & $\begin{array}{r}41 \\
7.3\end{array}$ & $\begin{array}{r}41 \\
6.7\end{array}$ & $\begin{array}{l}43 \\
10.5\end{array}$ & & $\begin{array}{r}42 \\
9\end{array}$ \\
\hline $\begin{array}{l}\text { Previous Light Therapy: } \\
\text { Yes } \\
\text { No }\end{array}$ & $\begin{array}{l}7 \\
3\end{array}$ & $\begin{array}{l}7 \\
4\end{array}$ & $\begin{array}{r}4 \\
16\end{array}$ & $\begin{array}{r}2 \\
12\end{array}$ & & $\begin{array}{l}20 \\
35\end{array}$ \\
\hline
\end{tabular}

${ }^{a}$ Each cell records the number of patients in the condition with the exception of cells that contain mean age and standard deviations.

${ }^{b}$ Includes those on antidepressants.

ren on the 30-minute condition than on the 60-minute ondition in Seattle, whereas approximately equal numbers were treated with each duration in Bethesda. Twenty-one subjects were treated with the 60-minute condition and 34 with the 30 -minute condition. Thirty patients were treated with the bright and 25 with the dim condition. The unequal number resulted from our attempt to randomize in a stratified way, taking into ccount medication status and prior exposure to light treatment.

Most of the patients $(84 \%)$ were women ( 27 of 30 $m$ the bright condition and 19 of 25 in the dim condibon). The mean age $( \pm S D)$ was virtually identical for tright and dim conditions ( $42 \pm 9.2$ and $42 \pm 9.1$ years, respectively). Most of the patients (53 of 55) met DSMM-R criteria for major depression and only two met orteria for bipolar depression. As can be seen in Table 1. 20 of 55 subjects had had prior exposure to light therpy and 29 of 55 patients were medication-free throughout the study. Although it was our intention to treat equal numbers of these different groups with bright and inlight, more unmedicated patients were treated with the bright visor than with the dim visor (19 vs. 10), though this difference did not reach statistical signifiance.

\section{Effects on Mood}

The mean baseline total SIGH-SAD scores $( \pm$ SD) for patients who received bright- and dim-light treatment were $31.0 \pm 6.6$ and $31.2 \pm 7.6$, respectively (NS). Corresponding posttreatment scores $( \pm \mathrm{SD})$ were $19.5 \pm$ 11.4 and $14.2 \pm 8.8$, and withdrawal scores were 22.5 \pm 10.1 and $28.4 \pm 10.4$. The mean baseline 21-item HDRS scores for patients who received bright and dim light were $16.8 \pm 4.3$ and $17.7 \pm 4.7$, respectively. Corresponding posttreatment scores were $11.0 \pm 5.9$ and $8.9 \pm 5.5$, and withdrawal scores were $13.2 \pm 5.5$ and $16.7 \pm 6.1$ (see Fig. $3 A$ and $B$ ).

Analysis of variance with repeated measures on the 21-item HDRS data showed a significant time-byintensity interaction $(F=5.16, d f=2, p<0.01$; see Fig. $3 \mathrm{~A}$ and $3 \mathrm{~B}$ ). Post-hoc $t$-tests showed this effect to be due almost entirely to differences in withdrawal values that were lower after the bright- than the dim-light treatment $(t=2.27, d f=53, p<0.05)$. Although pre- and posttreatment HDRS scores were significantly different for both dim and bright visors $(t=7.72, d f=24$, $p<0.001$; and $t=7.25 ; d f=29, p<0.001$, respectively), posttreatment and withdrawal values differed significantly only for the $\operatorname{dim}(t=5.72, d f=24, p<0.001)$, 
A

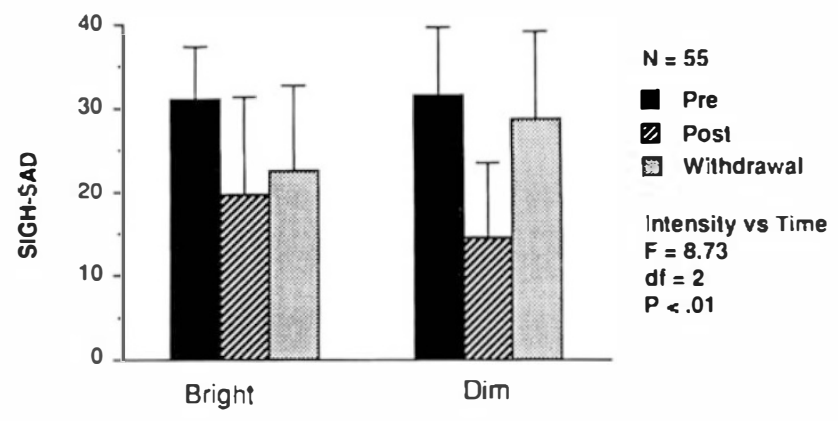

A

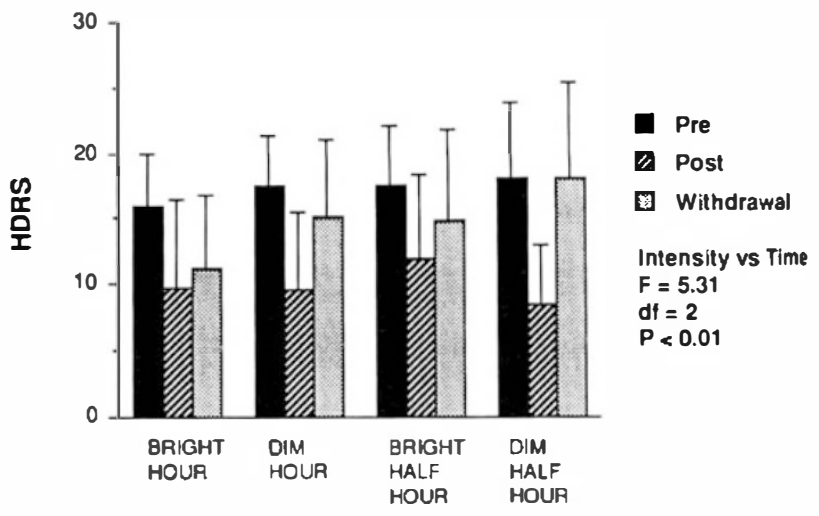

B

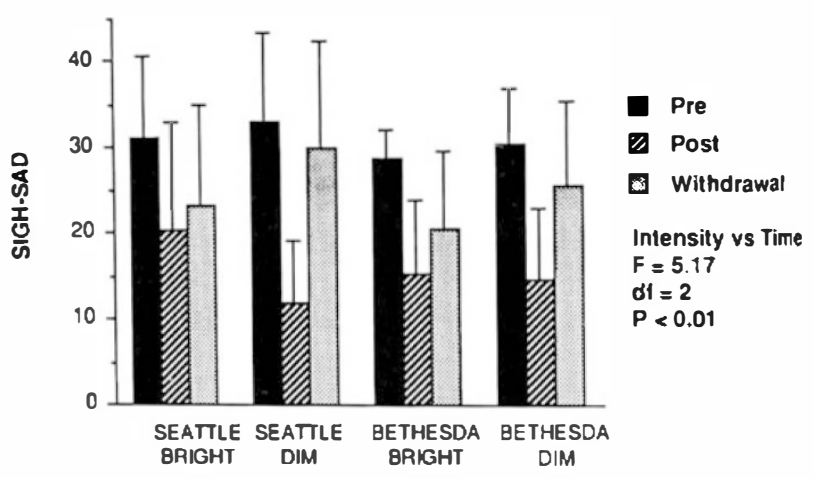

Figure 3. The SIGH-SAD (a) and 21-item HDRS (b) scores are shown for all 55 subjects treated with bright and dim visors before and after 1 week of treatment and after 1 week of withdrawal. There were significant time-by-condition interactions for both measures, both largely due to the greater withdrawal effect following dim-light treatment.

but not the bright visor $(t=1.54, d f=29)$. There was no interaction between duration and condition, suggesting no difference in efficacy between the 60-minute and the 30-minute treatment conditions. Similarly, there was no significant site-by-condition interaction (see Fig. 4A and B), nor any effect of a history of prior light treatment on outcome.

In evaluating the results according to the stringent response criteria of Terman et al. (1989), [reduction of HDRS scores to $\leqslant 50 \%$ of baseline and $<8]$ ), we found a tendency for the patients to respond better to the dim than to the bright visor, although this did not reach statistical significance (see Table 2). Thus, response rates for the dim visor were 7 of $11(63 \%)$ and 7 of 14 (50\%) for the 60-minute and 30-minute conditions, respectively. Corresponding values for the bright treatments were 4 of $10(40 \%)$ and 4 of $20(20 \%)$, respectively. When we combined both durations of treatment and took the stratification of treatment duration into account, we found the difference between groups reduced to a trend ( $p=0.07$, Mantel-Haenszel test, [Fleiss 1981]).

Figure 4. The 21-item (a) HDRS and SIGH-SAD (b) scores are shown for different durations of treatment at the two major sites, Bethesda and Seattle. The dim visor showed a slightly, but not statistically significant, greater effect than the bright visor, especially following the 30-minute treatment regimen and at the Seattle site.

We also examined response rates by looking at SIGH-SAD total scores, which incorporate atypical symptoms scores (Rosenthal and Heffernan 1986), and defined as responders those individuals whose totals were reduced to less than or equal to $50 \%$ of baseline, as has previously been suggested (Eastman et al. 1989) (see Table 2). With this approach, we found the response rates for the dim visor to be 7 of $11(63 \%)$ and 10 of $14(71 \%)$ for the 60 -minute and 30 -minute conditions, respectively. Corresponding values for the bright visor were 3 of $10(30 \%)$ and 9 of $20(45 \%)$, respectively. Analysis of the pooled data by Fisher's exact test with appropriate correction for multiple comparisons (Mantel and Haenszel 1959) again yielded results that fell just short of statistical significance for the combined treatment durations $(p=0.07)$.

\section{Other Self-Report Measures}

A priori expectations were quite positive for both types of visors, with average patient responses falling be 
Table 2. Comparison of Response Rates Following Treatment with Bright- vs. Dim-Light Visors

\begin{tabular}{|c|c|c|c|c|c|c|c|}
\hline & & \multicolumn{3}{|c|}{ HDRS } & \multicolumn{3}{|c|}{ SIGH-SAD } \\
\hline & & Responder $^{a}$ & Nonresponder & Response & Responder $^{b}$ & Nonresponder & Response \\
\hline \multirow[t]{2}{*}{ Hour } & Bright & 4 & 6 & $40 \%$ & 3 & 7 & $30 \%$ \\
\hline & Dim & 7 & 4 & $63 \%$ & 7 & 4 & $63 \%$ \\
\hline \multirow[t]{2}{*}{ Half Hour } & Bright & 4 & 16 & $20 \%$ & 9 & 11 & $45 \%$ \\
\hline & Dim & 7 & 7 & $50 \%$ & 10 & 4 & $71 \%$ \\
\hline \multirow[t]{2}{*}{ Pooled } & Bright & 8 & 22 & $36 \%$ & 12 & 18 & $40 \%$ \\
\hline & Dim & 14 & 11 & $56 \%{ }^{i}$ & 17 & 8 & $68 \%{ }^{c}$ \\
\hline
\end{tabular}

'Responder $=(\geqslant 50 \%$ reduction and $<8$ final score $)$.

'Responder $=(\geqslant 50 \%$ reduction in score $)$.

' $p=0.05$ Fisher Exact Test, $p \leqslant 0.07$ Mantel-Haenszel Chi Square.

tween expecting the light to improve their symptoms "moderately" and "quite a bit." There were no differences in expectations of the two visors and no correlation between expectations (as measured on a 5-point scale) and outcome for either bright- or dim-visor treatonents.

Side effects were reported with approximately equal frequency under both visor conditions (Table 3). The most commonly reported side effects were headxhe, eyestrain, and fatigue, although the last was attributed to the light visor in the minority of cases. Some patients reported feeling "wired" on both visor types; however, there were no cases of significant hypomania or mania.

The mean reported wake-up times $( \pm S D)$ before, during, and following treatment with the bright visor were 6:17 A.M. ( \pm 43 minutes), 6:13 A.M. ( \pm 43 minutes), and 6:18 A.M. ( \pm 57 minutes). Corresponding values for the dim-light visor were 6:06 A.M. ( \pm 83 minutes), 6:28 A.M. ( \pm 39 minutes), and 6:15 A.M. ( \pm 77 minutes). Analysis of variance revealed no significant main effects or interactions, and there was no trend toward significance.

\section{Pupillary Measurements}

At the Bethesda site, we photographed the eyes of 9 patients wearing bright visors and 10 other patients wearing dim visors, in both cases with the light sources on. The mean $( \pm S D)$ pupillary area of patients wearing the bright visor was $7.1 \pm 2.5 \mathrm{~mm}^{2}$ and of those wearing the dim visor was $12.8 \pm 4.5 \mathrm{~mm}^{2}$. These were significantly different $(t=-3.37, d f=17, p<.01)$.

The estimated total luminance of a dim visor was $180 \mathrm{~cd} / \mathrm{m}^{2}$ with a range of 30 to $200 \mathrm{~cd} / \mathrm{m}^{2}$ over the light-emitting surface. The estimated total luminance of a bright visor was $5000 \mathrm{~cd} / \mathrm{m}^{2}$ with a range of 300 to $25,000 \mathrm{~cd} / \mathrm{m}^{2}$ over the light-emitting surface. By multiplying total luminance values by average pupillary size, we estimated retinal illuminance. The mean retinal illuminance values for bright and dim visors were significantly different $\left(8.9 \times 10^{3}\right.$ and $5.7 \times 10^{2}$ trolands, respectively; $t=8.50, p=<0.001)$. There was no correlation between calculated retinal illuminance and antidepressant effects, as measured by change in the HDRS or SIGH-SAD scores.

Table 3. Side Effects of Visor ${ }^{a}$

\begin{tabular}{lccccc}
\hline & \multicolumn{2}{c}{ Side-Effect Frequency } & & \multicolumn{2}{c}{ Side-Effect Severity ${ }^{\boldsymbol{b}}$} \\
\cline { 2 - 3 } \cline { 5 - 6 } Side Effect & Bright & Dim & & Bright & Dim \\
\hline Abdominal Pains & $\mathbf{N}=\mathbf{2 3}$ & $N=\mathbf{2 0}$ & & $N=\mathbf{2 3}$ & $N=\mathbf{2 0}$ \\
Dizziness & $13 \%$ & $15 \%$ & & $0.26 \pm 0.75$ & $0.30 \pm 0.80$ \\
Eyestrain & $13 \%$ & $30 \%$ & & $0.17 \pm 0.49$ & $0.45 \pm 0.83$ \\
Fatigue & $39 \%$ & $45 \%$ & & $0.65 \pm 0.93$ & $0.70 \pm 0.92$ \\
Wired & $43 \%$ & $35 \%$ & & $0.83 \pm 1.11$ & $0.75 \pm 1.20$ \\
Headache & $22 \%$ & $20 \%$ & & $0.30 \pm 0.63$ & $0.35 \pm 0.75$ \\
Insomnia & $48 \%$ & $40 \%$ & & $0.70 \pm 0.87$ & $0.60 \pm 0.94$ \\
Muscle Aches & $22 \%$ & $30 \%$ & & $0.26 \pm 0.54$ & $0.60 \pm 0.99$ \\
Nausea & $22 \%$ & $30 \%$ & & $0.26 \pm 0.54$ & $0.25 \pm 0.44$ \\
Sweaty Palms & $17 \%$ & $15 \%$ & & $0.30 \pm 0.76$ & $0.25 \pm 0.72$ \\
\hline
\end{tabular}

${ }^{a}$ All values expressed as means \pm SD.

${ }^{b}$ Severity is rated on a scale of 0 to $3,0=$ absence of symptoms; $1=$ mild; $2=$ moderate; and 3 = severe. 


\section{DISCUSSION}

The SAD patients treated in the present study were clinically and demographically similar to those we have described previously (Rosenthal et al. 1984; Oren and Rosenthal 1992). The low prevalence of bipolar patients in this study (which stands in contrast to our earlier reports) stems from our change in diagnostic criteria over time from the Research Diagnostic Criteria (Spitzer et al. 1978), which have a relatively low threshold for the diagnosis of hypomania, to the DSM-III-R criteria (Spitzer et al. 1989), which require actual dysfunction as a result of hypomania for a patient to qualify for a bipolar diagnosis.

In this first clinical trial of the light visor, our hypothesis that the bright visor would be more effective than the dim one was not borne out. There was no statistical difference in efficacy between the two visors, regardless of how such efficacy was measured, although there was a trend toward a poorer response rate for the bright visor. There is thus no evidence that the light visor was effective, when efficacy is defined as producing a greater antidepressant effect than placebo. Although analysis of the SIGH-SAD ratings showed a significant interaction between phase of the study and intensity, this was not due to a difference in treatment effect but rather to a greater tendency to relapse following withdrawal from the dim than the bright visor.

Insofar as there was no difference in efficacy between the "active," (6000-lux) and "control" (400-lux) treatments, this study does not provide any direct evidence for a specific therapeutic effect of the bright visor. One explanation for the observed improvement in mood is that it was due entirely to a placebo effect. Alternatively, both treatments might have been biologically active and might have exceeded a therapeutic threshold. These same alternative possible explanations might be invoked to account for the results of two subsequent multicenter studies (Levitt et al. 1991; Teischer et al. 1992), where no differences in efficacy were observed across visor treatments of widely different intensities. On the basis of the present study and its two successors, there is no definitive way of deciding between the aforementioned competing explanations.

If the visor exerted its antidepressant effects by placebo mechanisms alone, how can this explanation be reconciled with earlier evidence that treatment with the light box was superior to placebo? One possible explanation is that the visor delivers light to the eyes less efficiently or from a smaller proportion of the visual fields than the light box. Thus, Gaddy et al. (1992) found a greater degree of melatonin suppression in normal subjects exposed to $4000 \mathrm{lux}$ at the surface of the cornea when the light source was a box than when it was a visor. That finding showed that simple measurement of corneal illumination is insufficient to predict the effects of light on melatonin suppression. On the other hand, bright light emitted from a visor is not without biologic effects. Thus, visor light at 4000 lux can significantly suppress nocturnal melatonin (Gaddy et al. 1992) and visor light at 3200 lux can significantly dampen the normal nocturnal decline in body temper. ature (Edelson et al. 1991).

Some have argued that the antidepressant response to the light box might also be nothing more than a placebo effect and have pointed out that a definitive placebo-controlled study of light-box therapy for SAD has yet to be done (Eastman 1990). Notwithstanding design flaws, differential effects of "active" and "control" light-box treatments have been found in several. although by no means all, light-box studies, including coniparisons of light of different intensities, timing and color, or exposure to different parts of the body (for review see Terman and Terman 1991; Oren and Rosenthal 1992). Such differential effects have not thus far been found in studies of the light visor. For this reason, there is less evidence to suggest a specific antidepressant effect for the light visor than for the light box.

The present study had some advantages over its predecessors. First, the number of subjects studied was relatively large. Second, expectations were measured ahead of time and were found to be no different for the two visors being studied. Finally, the multicenter na. ture of the study decreased the likelihood that the results obtained were specific to a particular center. Limitations of the study included: 1) incomplete log. ging of sleep (only wake-up times were registered). leaving open the possibility that different sleep patterns in the two visor conditions might have obscured poten. tial differences in efficacy (although antidepressant effects of sleep deprivation have not yet been well demonstrated in SAD); 2) imperfect control of the am. bient lighting environment in which subjects received their light therapy; and 3) since we asked patients to remain relatively stationary during treatment ses. sions, we were unable to evaluate whether the visor permitted free mobility at these times.

If the antidepressant effects of the light visor were specific, that is, not solely a result of a placebo effect. why did we not find the predicted relationship between intensity and response? This same question was ad. dressed by Terman (1991) in a discussion of the presentation of the subsequent light-visor study by Levitt et al. (1991). Even though subjects were shown exactly how we wanted them to position the visor, we had no way of knowing how well they complied with thesein. structions. Small differences in positioning of a light source close to the eye could result in large differences in the amount of light entering the pupil. Further modifications in the amount of light entering the pupil could result from squinting, lowering the eyelids, or changes in pupillary size. Such pupillary size changes 
might not have been detected by our measurement at a single point in time. Finally, we cannot rule out the possible confound of different retinal adaptations to different light intensities. If the similarity in response ates resulting from treatment with the different visors is not entirely due to a placebo effect, specific explanabions for the absence of an intensity response relationship are needed.

The response rates seen in this visor study (as defined by the strict criteria of Terman et al. (1989a): that $i$, a decrease to $<8$ on HDRS and a decrease to $\leqslant 50 \%$ abaseline) were $56 \%$ and $36 \%$ for the 400 -lux and 6000 bux visors, respectively. In the later multicenter study on 105 SAD patients, Levitt et al. (1991), reported reponse rates (defined only slightly differently as HDRS $48, \leqslant 50 \%$ of baseline) for visors of 60 -lux, 600 -lux, and $3600-$ lux intensity to be $52 \%, 45 \%$, and $50 \%$, respecively. In the later multicenter study on 57 patients, Teischer et al. (1992) reported response rates (HDRS $\langle 8, \leqslant 50 \%$ of baseline) for red-visor treatments of 30 tuxintensity and white-visor treatments of 600-lux inmsity to be $50 \%$ and $36 \%$, respectively. In none of the three visor studies undertaken to date were response rates significantly different across treatment conditions.

The response rate seen with the 400-lux visor in the present study $(56 \%)$ is similar to those found in several previous studies with 2500-lux light boxes, greater than those found with previous placebo treatments or lighting conditions regarded as inactive, but less than treatments with 10,000-lux light boxes (Rosenthal and Moul 1990; Terman 1991). This information may be useful to dinicians faced with the decision of recommending a treatment intervention to a patient; however, it does oot speak to whether the light visor is acting solely as aplacebo or in a specific way as well.

It is clear that the method of ocular exposure can becritical in determining whether or not a light stimutos will induce a specific effect, quite independent of the illuminance of the stimulus. For example, Lewy et d. (1980) found that light of 2500 lux or more was required to suppress nocturnal human melatonin secrecion. Later, however, Brainard et al. (1988) found that when they carefully controlled ocular exposure, pupilbry size, and stimulus characteristics, nocturnal plasma elatonin could be strongly suppressed with as little a 15 to 20 lux. Thus the method of light presentation may be more important than its absolute illuminance (bux) value in determining its biologic or therapeutic efleacy

We did not predict that we would find different responses to withdrawal following treatment with the two different visors, however such a result has been kported in at least one previous study of light therapy. Thus, Wirz-Justice et al. (1986) showed greater and more mid relapse following withdrawal from a dim- than tom a bright-light treatment. In reviewing the literature on crossover studies of light therapy, we have noted lower baseline depression levels for the second treatment condition when the less effective treatment follows the more effective one than when the order is reversed (Rosenthal et al. 1988). This would suggest a greater carry-over effect following the more effective treatment. It is difficult to reconcile these earlier observations with those from the present study since treatment with the bright visor, which was followed by less relapse than treatment with the dim visor, was not more effective.

In conclusion, the results of the present study offer controlled data on the efficacy of a novel light delivery system in a large number of SAD patients treated at three separate centers. Although both patients and clinicians believed the visor to be a clinically effective treatment, its true efficacy, as defined by superiority to a control treatment, was not established. If it is not purely a placebo, then the apparent absence of a relationship between intensity and response, such as has been described for earlier light-box treatment studies, has yet to be explained. It may emerge that the mode of presentation of light, not merely the intensity, is an important understudied area of light therapy.

\section{ACKNOWLEDGMENT}

This study was funded in part by Bio-Brite, a company licensed to manufacture and distribute the light visor. Three of the co-authors (NER, TAW and GCB) are potential coinventors of the light visor, for which one patent has been granted $(\# 4,911,166)$ and others are pending. The authors wish to thank Drs. Morris Waxler of the Food and Drug Administration and Craig Bernecker of the Department of Architectural Engineering of Pennsylvania State University for their preliminary estimates of light box and visor luminances and for their advice.

\section{REFERENCES}

Borkovec TD, Nau SD (1972): Credibility of analogue therapy rationales. J Behav Ther Exp Psychiatry 3:257-260

Brainard GC, Lewy AJ, Menaker M, Fredrickson RH, Miller LS, Weleber RG, Cassone V, Hudson D (1988): Doseresponse relationship between light irradiance and the suppression of plasma melatonin in human volunteers. Brain Res 454:212-218

Checkley S, Winton F, Franey C, Arendt J (1986): Effects of Phototherapy Upon Mood and Melatonin in Seasonal Affective Disorder. London, Royal College of Psychiatry

Eastman CI (1990): What the placebo literature can tell us about light therapy for SAD. Psychopharmacol Bull 26:495-504

Eastman C, Lahmeyer HW, Watell LG (1989): The Placebo Problem in Phototherapy for SAD. Bethesda, MD, Society for Light Treatment and Biological Rhythms

Edelson MI, Tirney SP, Gaddy JR, Stewart KT, Brainard CC 
(1991): Effect of light intensity on oral, rectal, and tympanic temperature and full body activity. Sleep Res 20:454

Fleiss JL (1991): Statistical Methods for Rates and Proportions. New York, Wiley

Gaddy JR, Edelson M, Stewart K, Brainard GC, Rollag MD (1992): Possible retinal spatial summation in melatonin suppression. In Holick M, Kligman A (eds), Biological Effects of Light. Berlin, Walter de Gruyter

Hamilton M (1967): Development of a rating scale for primary depressive illness. Br J Soc Clin Psychol 6:278-296

Isaacs G, Stainer DS, Sensky TE, Moor S, Thompson C (1988): Phototherapy and its mechanisms of action in seasonal affective disorder. J Affect Disord 14:13-19

James SP, Wehr TA, Sack DA, Parry BL, Rosenthal NE (1985): Treatment of seasonal affective disorder with light in the evening. Br J Psychiatry 147:424-428

Kaufman J, Christensen J(1987): IESLighting Handbook. New York, Illuminating Engineering Society

Levitt AJ, Joffe RT, Martin LS, Moul DE, Lam RW, Teischer MH, Lebegue B, Oren DA, Buchanan A, Glod CA, Murray MG, Brown J (1991): Light Visor Treatment of SAD. Toronto, Society for Light Treatment and Biological Rhythms

Lewy AJ, Wehr TA, Goodwin FK, Newsome DA, Markey SP (1988): Light suppresses melatonin secretion in humans. Science 210:1267-1269

Mantel N, Haenszel W (1959): Statistical aspects of the analysis of data from retrospective studies of disease. JNCI 22:719-748

Oren DA, Rosenthal NE (1992): Seasonal affective disorders. In Paykel ES (ed), Handbook of Affective Disorders, ed 2. London, Churchill Livingstone, pp 551-567

Rosenthal NE, Heffernan MM (1986): Bulimia, carbohydrate craving, and depression: A central connection? In Wurtman RJ, Wurtman JJ (eds), Nutrition and the Brain, Vol. 7. New York, Raven Press

Rosenthal NE, Moul DE (1990): Response from the investigators. Light Treat Biol Rhythms 2:3-4

Rosenthal NE, Sack DA, Gillin JC, Lewy AJ, Goodwin FK, Davenport Y, Mueller PS, Newsome DA, Wehr TA (1984): Seasonal affective disorder: A description of the syndrome and preliminary findings with light therapy. Arch Gen Psychiatry 41:72-80

Rosenthal NE, Sack DA, Carpenter CJ, Parry BL, Mendelson WB, Wehr TA (1985): Antidepressant effects of light in seasonal affective disorder. Am J Psychiatry 142:163-170

Rosenthal NE, Sack DA, Skwerer RG, Jacobsen FM, Wehr TA (1988): Phototherapy for seasonal affective disorder. J Biol Rhythms 3:101-120
Spitzer RL, Endicott J, Robins E (1978): Research and diagnostic criteria: Rationale and reliability. Arch Gen Psychiatry 35:773-782

Spitzer RL, Williams JB, Gibbon M, First MB (1989): Structured Clinical Interview for DSM-III-R-patient edition (SCID-P, 9/1/89 version). New York, Biometrics Research Department, New York State Psychiatric Institute

Stewart KT, Gaddy JR, Benson DM, Byrne B, Doghramij K, Brainard GC (1990): Treatment of winter depression with a portable head-mounted phototherapy device. Prog Neuropsychopharmacol Biol Psychiatry 14:569-578

Teischer MH, Glod CA, Oren DA, Luetke CJ, SchwartzP, Brown C, Rosenthal NE (1992): The phototherapy light visor: There is more to it than meets the eye. Bethesda, MD, Society for Light Treatment and Biological Rhythms

Terman M (1991): Clinical efficacy of the light visor, and its broader implications. Light Treat Biol Rhythms 4:37-40

Terman M, Terman JS (1991): Light therapy for winter depression: Report to the depression guidelines panel, P.H.S. agency for health care policy and research. New York, Public Health Services, New York State Psychiatric Institute

Terman M, Terman JS, Quitkin FM, McGrath PJ, StewartJW Rafferty B (1989a): Light therapy for seasonal affective dis. order: a review of etticacy. Neuropsychopharmacology $2: 1-22$

Terman M, Terman JS, Schlager D, Rosofsky M, Quitkin FM (1989b): 30 minute light therapy at 10,000 lux. Bethesda. MD, Society for Light Treatment and Biological Rhythms

Thorington L (1985): Spectral, irradiance and temporal aspects of natural and artificial light. In Wurtman R, Baum M, Potts P (eds), The Medical and Biological Effects of Light. New York, NY Academy of Science, pp 28-54

Wehr TA (1990): Effects of wakefulness and sleep on depression and mania. In Montplaisir J, Godbout R (eds), Sleep and Biological Rhythms. New York, Oxford University Press, pp 42-86

Williams JBW, Link MJ, Rosenthal NE, Terman H (1988): Structured interview guide for the Hamilton depression rating scale seasonal affective disorders version (SIGH. SAD). New York, New York State Psychiatric Institute

Wirz-Justice A, Bucheli C, Graw P, Kielholz P, Fisch H-L' Woggon B (1986): Light treatment of seasonal affective disorder in Switzerland. Acta Psychiatr Scand 74:193-204

Wyszecki G, Stiles W (1982): Color Science. New York, John Wiley 